\title{
Correction of Children's Singing Voice Building Problems at Music Primary School in Hungary
}

\author{
Andrea Asztalos \\ Doctoral School of Education, Eötvös Loránd University, Budapest, Hungary
}

\begin{abstract}
This paper outlines a novel approach to studying children's singing that enables a more accurate and global picture to be drawn of children's actual level of singing achievement across a range of tasks. The purpose of this paper was to observe and examine the problems of singing voice production of children aged 10 to 12 years and describe how we can develop children's singing voice quality. It draws on a two-year longitudinal field study of children aged 10 to 12 years. In the pre-research we have selected thirty 5th grader children with singing problems from seventy 5th grader children. In the experimental group and in the controll group participated 15-15 children (10-10 girls and 5-5 boys) aged 10 to 12 years. All the children attended the same Music Primary School in Budapest. The first phase tested children singing individually short fragments, examined the singing voice quality and singing problems. We observed four different kinds of children's singing voice building problems and devised experimental exercises for all problems. The second phase, conducted two years later, repeated these patterns with some minor procedural improvements. Research methods were observations, experiment, rating scales. Data were analyzed using qualitative analysis. Conclusion: In two years, all singing problems were breaked off. A well-planned and efficiently executed exercises are essential for developing a good singing habit. Bescause the vocal cord is an extremely sensitive organ, it needs special care and trainig in order to have good voice production.
\end{abstract}

\section{Introduction}

Singing is often the window to the young child's musical life. Children love to sing. Listen to children as they are playing on a playground. When they are playing any type of game with other children, the game is often accompanied by a song or chant. Singing is an essential part of childhood and of growing up. Singing, probably uniquely, involves the integration of musical, speech, visual, motor and emotional systems of the brain. [22].

Every child has the ability to sing; the voice is the most accessible musical instrument. Regardless of social background, race, or musical ability, the voice is the one instrument that is available to all children. Singing has a significant impact on a child's intellectual developemnt. Singing facilitates language development through the performance of beat and rhythm in music. Singing helps children learn and articulate the text of a song; it facilitates memory, as wel as the development of vocabulary [22].

\section{Development of Singing Ability}

The common roots of singing and speaking are the nonverbal vocalization of the infant, which are an immediate expression of its basic feelings. Parents intuitively tune in to the child's noises to establish communication with the infant. These child-directed vocalizations are called motherese and can be seen as a prelinguistic alphabet [14]. These nonverbal vocalizations represent at the same time prelinguistic and premusical means of expressions.

A number of authors agree on the fact that most of these melodic contours consist of descending glissando figures after the first 3 or 4 months of life [5]. Papousek [15] describes four different types of melodic contours of vocalization in early childhood (descending, ascending-descending, ascending and complex, and repeated ascending and descending), the frequency of which depends on the age of the infant and the situational context. Descending contours prevail in the first months of life, but later the melodic contours become more varied and the proportion of other contours increases.

By the end of the first year of life, it becomes possible to separate singing and speaking in the preverbal vocalizations of most children. Children themselves experiment with the voice and seem to try out its range and possibilities in ,vocal play” [18]. It is possible to understand vocal play in Piagetian terminology as a kind of sensorimotor play. This kind of behavior typically appears between the 12th and the 18th month of life. The two fundamental cognitive processes that underlie vocal play and imitation are assimilation and accommodation [18]. Accommodation takes place when children are trying to adapt their imagination and vocal expression to a given model such as the phrase of a song. Assimilation occurs when children receive new information (a new melody) and integrate it into an already-existing schema. 
Another kind of singing was characterized by Dowling [3] as an articulation of syllables with vowels that are slightly prolonged and appear on stable pitches. The author alsoobserved a sequential organization of the song, referring to more or less stabilized tonal patterns. According to Dowling, the first actual singing can be observed between the 6th and the 18th month of life. At first, these glissandolike improvisations on single syllables occupy only a narrow pitch range. Later they turn into recognizable songs, often with a sequential organization of the sounds. Thus a typical song of an 18-month-oldchild consists of an often-repeated phrase with a steady melodic contour at a continuously changing level of pitch. The song is quite often interrupted by breathing; however, the rhythmical contour remains within the phrase and sometimes even stretches over several phrases. These songs are often derived from the rhythm of language.

In their second year of life, children are able to sing single short phrases of a song, frequently turning them into spontaneous improvisations and repeating them quite often [6]. Microtonal figures in spontaneous singing slowly make way for more accurate intervals, resulting in an overall impression that is clearly related to the diatonic system [13]. Between the ages of 3 and 4, children combine different songs and song fragments into something like a medley. They can repeat songs they hear and increase phrase contour of the presented song by trial and error. Other researchers observed that children could reproduce all of the lyrics, the main rhythms, and also the formal segments of a song starting at the age of 4 [17].

Children will have acquired the singing range of an octave with all its steps once they are 6 or 7 years old [1], [12]. Although they still might miss certain pitches, this does not mean they are unable to recognize the pitches. The development of the ability to sing comes to an end around the age of 8 years. Generally, by this time children are able to sing a song correctly. This ability remains at this level unless music instruction and practice follow. As always, however, a broad range of interindividual differences are observable. The singing abilities of untrained adults are not much different from those of 8 to 10 -years-old children [1], [12], [18].

According to Stadler [19] the different concurrent theoretical approaches to the development of singing can be categorized into three groups. The first group comprises the speech-dominated theories of sequence. The principal argument here is that songs are learned in a certain order, namely, lyrics, rhythm, melody contour/phrases, precise intervals [8], [13], [21]. A second group consists of explanations that implicate the order of intervals. Here intervals or successions of notes appear developmentally in a specific and unreversible succession, namely, first the fifth, followed by the third and fourth and then the sixth. This theory assumes innate structures that are supposedly based on the acoustical properties of the harmonic series [11]. The third group could be labeled contour theories. Proponents of this approach advance the notion that the learning process begins with the melodic contour and that pitch and tonality follow. Learning to sing is thus assumed to proceed from global to more local features. According to Davidson's [1] theory of contour schemata, the development of a contour schema starts with a falling third into which the other intervals are placed. The contour schema will then expand with the child's age: at first to a fourth and up to a sixth, which is mastered by the age of around 6 or 7 . One author suggests the following course of development [18]:

1. Early beginnings; vocalizations as the expression of an infant's basic feelings.

2. Shifted imitations; development of rituals and extended vocal play.

3. Imitation without understanding of rules and inventing of arbitrary rules.

4. Generalization of examples; ability to sing larger units

5. Implicit integration of conventional rules into actions; increasing control of one's own singing.

6. Beginning reflecting on one's own actions, means, symbols and terms; use of notation for the production and reproduction of music.

\subsection{Analysing of Singing Ability}

Researchers have been interested in children's singing since the start of the twentieth century, yet the focus of enquiry has shifted. Prior to the 1970s, researchers typically attempted to assess children's musicality through batteries of tests, thereby differentiating between „musical” and „unmusical” children. Where these tests were used in school, children who sang out of tune were often assumed to be 'unmusical' and unlikely to be to be offered further musical training such as singing in choirs and learning to play musical instruments. However, two influential studies by Davies and Roberts [2] changed the emphasis from this deficit approach with the finding that some children categorised as 'monotones' by their music teachers were able to sing relatively well when tested individually. They also began to develop training to help these children improve their singing.

More recently, as a consequence of this shift of emphasis, singing development has been theorised as a continuum. It is argued that children pass through successive phases, subject to appropriate opportunities being available [6], [20]. Within these accounts, children who sing "out of tune" are considered as developing singers, capable of 
benefiting from instruction, and research has focused on exploring the optimal conditions for teaching and assessing children's singing.

The methods of analysing the singing that the children produce have also varied. Many researchers have used rating scales, where the assessor chooses the statement that best reflects what he or she has heard. Multiple aspects of singing can be scored this way, such as singing voice use and rhythmic elements [10], or pitch accuracy and interval accuracy [7], or singing voice use [16].

The children's singing development has typically been studied cross-sectionally, with models of developing singing based on different levels of performance from children of different ages [10], [4], [7] However, the large amount of individual variability found in a group of children of any given age suggests that a longitudinal approach would be more illuminating in terms of tracing development [7].

\subsection{Kodály Method}

The Kodaly Method is a way of developing musical skills and teaching musical concepts beginning in very young children. This method uses folk songs, Curwen hand signs, pictures, movabledo, rhythm symbols and syllables. It was first introduced in Hungary but is now used in many countries, either alone or in combination with other methods.

The voice is the main musical instrument of this method. In his words, Singing connected with movements and action is a much more ancient, and, at the same time, more complex phenomenon than is a simple song. Various rhythm and tonal instruments are also used, including xylophones and recorders. Although the Kodaly Method follows a set sequence, the materials used in teaching musical concepts varies depending on the age of the student. The sequence followed may be simplified as: listen - sing - understand - read and write - create.

We should first learn to love music as human sound and as an experience that enriches life. The voice is the most natural instrument and one which every person possesses. Kodály called singing "the essence" of this concept. Singing is a powerful means of musical expression. What we produce by ourselves is better learned; and there is a stronger feeling of success and accomplishment. Learning through singing should precede instrumental training. It is in the child's best interest to understand the basics of reading music before beginning the difficult task of learning the technique of an instrument. Singing best develops the inner, musical ear. If we ourselves sing often, this provides a deep experience of happiness in music. Through our own musical activities, we learn to know the pulsation, rhythm, and shape of melody. The enjoyment given encourages the study of instruments and the listening to other pieces of music as well).

In the classroom we can encourage singing for enjoyment and at the same time promote correct intonation and a proper singing tone. The instructor's vocal example can significantly improve students' singing and the development of good vocal intonation. Young voice have less volume, less endurance, and naturally higher ranges than adult voices. The adult instructor must modify his or her voice to accommodate this. Male instructors should consider singing in a falsetto range until young students are able to match pitch. [9].

A capella singing will allow children to hear their own voices and enjoy active music making. Kodály addressed the importance of a capella singing.

When teaching music to children consider the following vocal ranges. These ranges are only suggestions, but might help teachers select appropriate repertoire for their students. [9]

Table 1. Children's vocal skills and ranges

\begin{tabular}{|c|c|c|}
\hline Grade & Vocal Skills & $\begin{array}{l}\text { Vocal } \\
\text { Range }\end{array}$ \\
\hline $\begin{array}{l}\text { Pre- } \\
\text { Kingergarten }\end{array}$ & $\begin{array}{l}\text { Perform child's } \\
\text { chants and say } \\
\text { nursery rhymes } \\
\text { with voice } \\
\text { inflection. }\end{array}$ & \\
\hline Kindergarten & $\begin{array}{l}\text { Understands the } \\
\text { concept of singing } \\
\text { and speaking } \\
\text { voice. }\end{array}$ & $\begin{array}{l}\text { Sing in tune } \\
\text { from D-B (D } \\
\text { above } \\
\text { middle C) } \\
\text { This range } \\
\text { could be } \\
\text { lower or } \\
\text { higher for } \\
\text { some } \\
\text { children. }\end{array}$ \\
\hline Grade 1 & $\begin{array}{l}\text { Develop head } \\
\text { voice. More control } \\
\text { of pitch. }\end{array}$ & \\
\hline Grade 2 & $\begin{array}{l}\text { More control of } \\
\text { head voice. } \\
\text { Perform simple } \\
\text { canons or melodic } \\
\text { ostinati in tune. }\end{array}$ & $\begin{array}{l}\text { Sing in tune } \\
\text { from } C \text { to } \\
\text { hugh } D .\end{array}$ \\
\hline Grade 3 & $\begin{array}{l}\text { Greater expressive } \\
\text { control of voice. } \\
\text { Can sing simple } \\
\text { canons and two } \\
\text { part songs in tune. }\end{array}$ & $\begin{array}{l}\text { Can sing up } \\
\text { to high Eb. }\end{array}$ \\
\hline Grade 4 & $\begin{array}{l}\text { More resonance in } \\
\text { voice. Can begin to } \\
\text { perform three-part } \\
\text { songs. }\end{array}$ & $\begin{array}{l}\text { Can sing up } \\
\text { to high } \mathrm{E} \text {. }\end{array}$ \\
\hline
\end{tabular}




\section{Aims}

The purpose of this paper was to observe and examine the problems of singing voice production of children aged 10 to 12 years and describe how we can develop children's singing voice quality. This paper outlines a novel approach to studying children's singing that enables a more accurate and global picture to be drawn of children's actual level of singing achievement across a range of tasks. It enables predictions to be made about their potential singing development in a formal school setting.

\section{Participants}

In the pre-research we have selected thirty 5 th grader children with singing problems from seventy 5 th grader children. In the experimental group and in the controll group participated 15-15 children (10-10 girls and 5-5 boys) aged 10 to 12 years. All the children attended a Music Primary School in Budapest. The experimental children have had individual vocal traininig lessons, 20 minutes a week.

\section{Methods}

The first phase tested children singing individually short fragments, examined the singing voice quality and singing problems. Tested children singing individually short fragments. Research methods were observations and experiment. We have used own rating scales. Examined the singing voice quality and singing problems. Devised experimental exercises for all problems. After a three-month teaching phase (end of the first phase) tested their singing individually with using of own rating scales. The research comprised a field study in order to explore features of children's singing in the real-life setting of school.

The second phase conducted two years later, repeated these patterns with some minor procedural improvements. This provided a longitudinal dimension to the project. Research methods were observations, experiment. Data were analyzed using qualitative analysis. It draws on a two-year longitudinal field study of children aged 10 to 12 years.

\section{Results}

The first phase tested seventy children singing individually short fragments, examined the singing voice quality and singing problems with using of own rating scales.

We observed four different kinds of children's singing voice problems: 1 . isolated chest-voice in singing; 2 . pressed singing voice; 3 . too airy, veiled singing voice; 4 . skinny singing voice.

We have selected $15-15$ children with singing problems.

Table 2. Participants

\begin{tabular}{|l|l|l|l|l|}
\hline & \multicolumn{2}{l|}{$\begin{array}{l}\text { Experimental } \\
\text { group }\end{array}$} & \multicolumn{2}{l|}{ Control group } \\
\hline $\begin{array}{l}\text { Vocal } \\
\text { problem }\end{array}$ & girls & boys & girls & boys \\
\hline $\begin{array}{l}\text { isolated } \\
\text { chest voice } \\
\text { in singing }\end{array}$ & 2 & 1 & 2 & 1 \\
\hline $\begin{array}{l}\text { pressed } \\
\text { singing } \\
\text { voice }\end{array}$ & 2 & 2 & 2 & 2 \\
\hline $\begin{array}{l}\text { too airy } \\
\text { veiled } \\
\text { singing } \\
\text { voice }\end{array}$ & 3 & 2 & 3 & 2 \\
\hline $\begin{array}{l}\text { skinny } \\
\text { singing } \\
\text { voice }\end{array}$ & 3 & 0 & 3 & 0 \\
\hline
\end{tabular}

We devised experimental exercises for all problems. A single exercise can be used to address multiple vocal and musical considerations. The exercises provided address matters of breath, vocal production, vowel formation, and vocal development. Each exercise is labeled with its fundamental purpose, although many function in several capacities.

\subsection{Isolated chest-voice in singing}

Reasons of this vocal problem: isolated chestvoice, full vibration without border vibration.

There are following problems in posture, in breathing, in articulation and in vocal sound:

- bodily overvoltage; more strained bodyposture; high elongated head-posture; protruded chin, mandible; hoisted shoulders;

- $\quad$ high breathing;

- too big mouth opening;

- too loud singing; too low singing; poor high tons; voice cracks in the area of register transition; less elasticity in singing; less flexibility in singing; poor dynamics; less expressive capabilities.

Correction of problems: correction of bodyposture; correction of head-posture; relaxation of mandible; midriff activation; deep breathing; articulation exercises; singing with feeling of gape and feeling of smile; singing in „mezza voce”; singing piano; development of singing voice from head-register, from head-voice; glissando exercises; vocal exercises with following vowels: „i”, „e”, (,„ü”, „ö"), „,o", „u” and the most conductive consonants: 
„n”, „m”,"ng”, ,s”; singing softly, singing in higher register.

In the first phase of the research the posture, breathing, articulation and vocal sound of the experimental children were developed to little better level. By one girl the posture and breathing were developed to medium level. The posture, breathing, articulation and vocal sound of control children were not developed in the first phase. In the second phase: the posture, breathing, articulation and vocal sound of the experimental children were developed to perfect level. In two years this singing problem was breaked off. By control children the posture, breathing, articulation and vocal sound could be developed at best to medium level in the second phase. One child's problems of posture, breathing, articulation and vocal sound were developed nothing. (see Diagram 1)

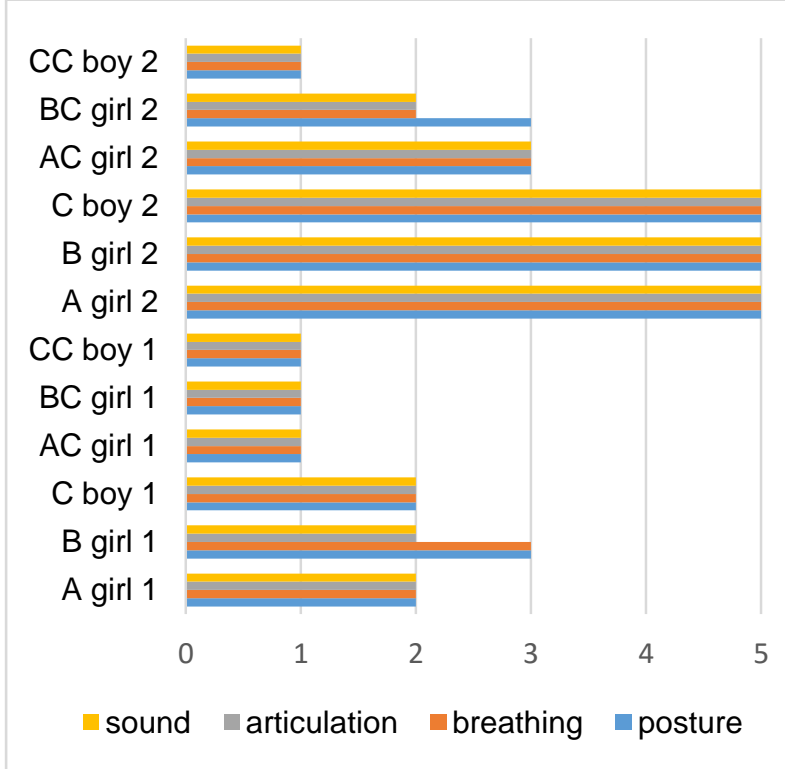

\section{Diagram 1. Correction of isolated chest voice in singing}

1 = wrong, 2 = little better, 3 = medium, 4 = good $5=$ perfect

\subsection{Pressed singing voice}

Reasons of this vocal problem: too much breath pressing and blow-pressing blast the vocal cords.

There are following problems in posture, in breathing, in articulation, in singing and in vocal sound:

- stiff, strained posture; cramped neck, shoulders, hands, elbows and throat; strained and tense ventral- wall; too raised head; high-ranking larynx; hoisted shoulders; protruded chin, mandible;

- inactiv midriff;

- $\quad$ stare facial expression;
- cramped and pressed singing voice; poor head-voices; hard tune starting, raspyvoiced; too big volume; poor flexibility in singing; hard impulse of singing; registerdivergence; little vocal register; intonation problems.

Correction of problems: correction of bodyposture; correction of head-posture; relaxation of mandible; relaxation of face-muscles; bodily relaxation; small head-movements (yes-no, rightleft); shaker-movements (hand-, and elbowmovements); relaxation of respiration; breathing is not damed; breath flow, stream; articulation exercises; sing softly; sing with movements; vocal exercises with following vowels: „u”, „o" and the most conductive consonants: „p”, ,t”, „k",,f”, „s”, „m”, „n”; sing with more head-voice; sing songs with facile and softly characters.

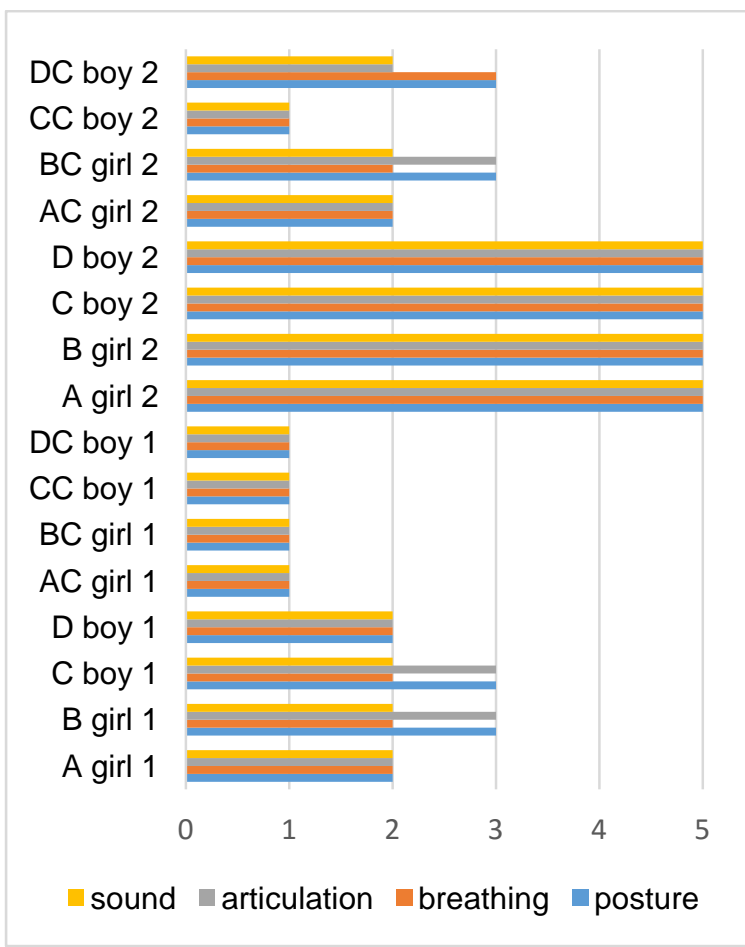

\section{Diagram 2. Correction of pressed singing voice}

1 = wrong, 2 = little better, 3 = medium, 4 = good $5=$ perfect

In the first phase of research the posture, breathing, articulation and vocal sound of the experimental children were developed to little better level. By two children the posture and articulation were developed to medium level. The posture, breathing, articulation and vocal sound of control children were not developed in the first phase. In the second phase: the posture, breathing, articulation and vocal sound of the experimental children were 
developed to perfect level. In two years this singing problem was breaked off. By control children the posture, breathing, articulation and vocal sound could be developed to little better level. By two children the posture and articulation and posture and breathing could be developed to medium level in the second phase. One child's problems of posture, breathing, articulation and vocal sound were developed nothing (see Diagram 2).

\subsection{Too airy, veiled singing voice}

Reasons of this vocal problem: the vocal cords can't close complete and breathing air escapes audible.

There are following problems in posture, in breathing, in articulation, in singing and in vocal sound:

- $\quad$ shrunken posture;

- $\quad$ poor breathing support; high-breathing;

- small lips activity; poor mimic; poor articulation;

- $\quad$ too airy, veiled singing voice; little singing voice volume.

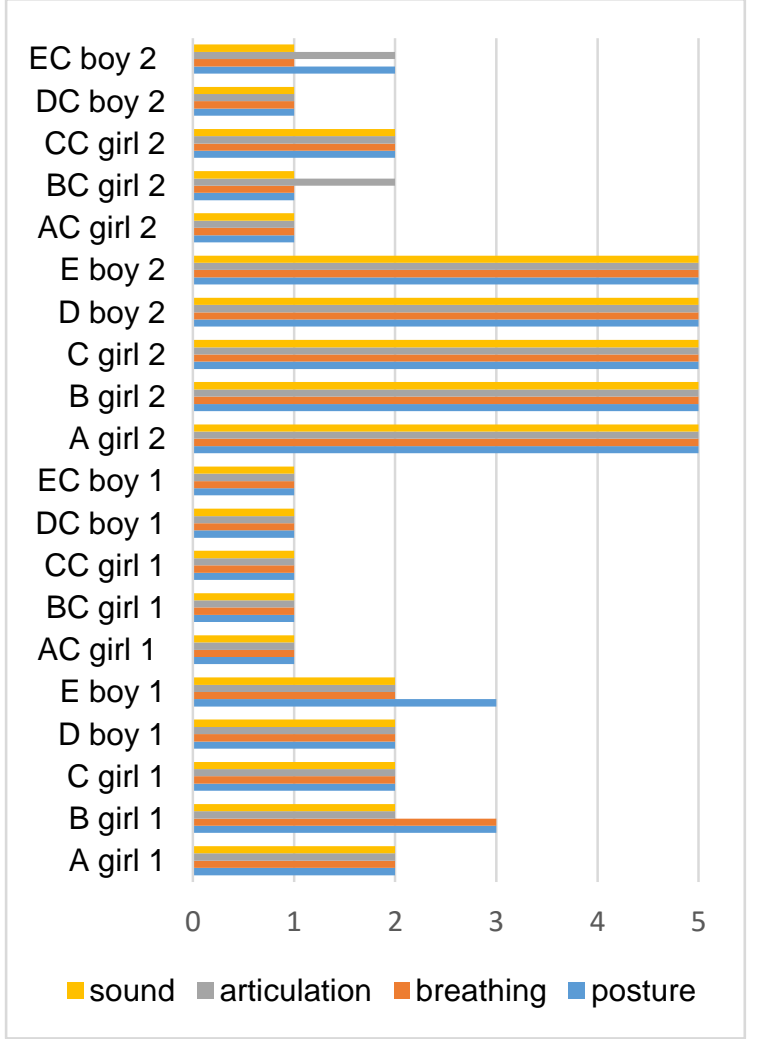

\section{Diagram 3. Correction of airy, veiled singing voice}

1 = wrong, 2 = little better, 3 = medium, 4 = good

$5=$ perfect
Correction of problems: straighten of body posture; body-posture activation; inhale with wondering; staccato exercises; sing with feeling of inhalation; sing with feeling of draw; mouth opening (long, narrow); chewing movements; articulation exercises; vocal exercises with following vowels: „i”, „e”, „ü” and the most conductive consonants: „b”, „d", „g","r"; affected, dramatically singing; sing with different timbres; sing songs with more cheerful or more verve characters.

In the first phase of the research the posture, breathing, articulation and vocal sound of the experimental children were developed to little better level. By two children the posture and breathing were developed to medium level. The posture, breathing, articulation and vocal sound of control children were not developed in the first phase. In the second phase: the posture, breathing, articulation and vocal sound of the experimental children were developed to perfect level. In two years this singing problem was breaked off. By control children the posture, breathing, articulation and vocal sound could be developed at best to little better level in the second phase. Two children's problems of posture, breathing, articulation and vocal sound were developed nothing. (see Diagram 3).

\subsection{Skinny singing voice}

Reasons of this vocal problem: mouth's inner space and resonance are less innervate.

There are following problems in posture, in breathing, in articulation, in singing and in vocal sound:

- $\quad$ phlegmatic body posture; not concentrated posture; poor body encouragement;

- high-breathing; poor breathing support;

- too small breath-movements; poor articulation; small and too wide mouthopening;

- too infantile voice; little singing voice volume; sometimes too airy vocal sound; little singing voice register; singing without overtones, chip sound.

Correction of problems: body-posture activation; big hand movements; breathing intensification; midriff activation; staccato exercises; mouth opening softly and vertical; feeling of width in mouth and in throat; singing with feeling of gape; singing with inner smile; chewing movements; articulation exercises; affected singing and playing; vocal exercises with following vowels: „u", „o", ,a" and the most conductive consonants: „, ,", ,d”, ,g”,,,m”, „n”, „r,; lilt singing with innervate characters.

In the first phase: the posture, breathing, articulation and vocal sound of the experimental children were developed to little better level. By two children the posture and breathing were developed to medium level. The posture, breathing, articulation 
and sound of control children were not developed in the first phase. In the second phase: the posture, breathing, articulation and sound of the experimental children were developed to perfect level. In two years this singing problem was breaked off. By control children the posture, breathing, articulation and vocal sound could be developed to little better level. By one children the posture and breathing could be developed to medium level in the second phase. One child's problems of posture, breathing, articulation and vocal sound were developed nothing (see Diagram 4).

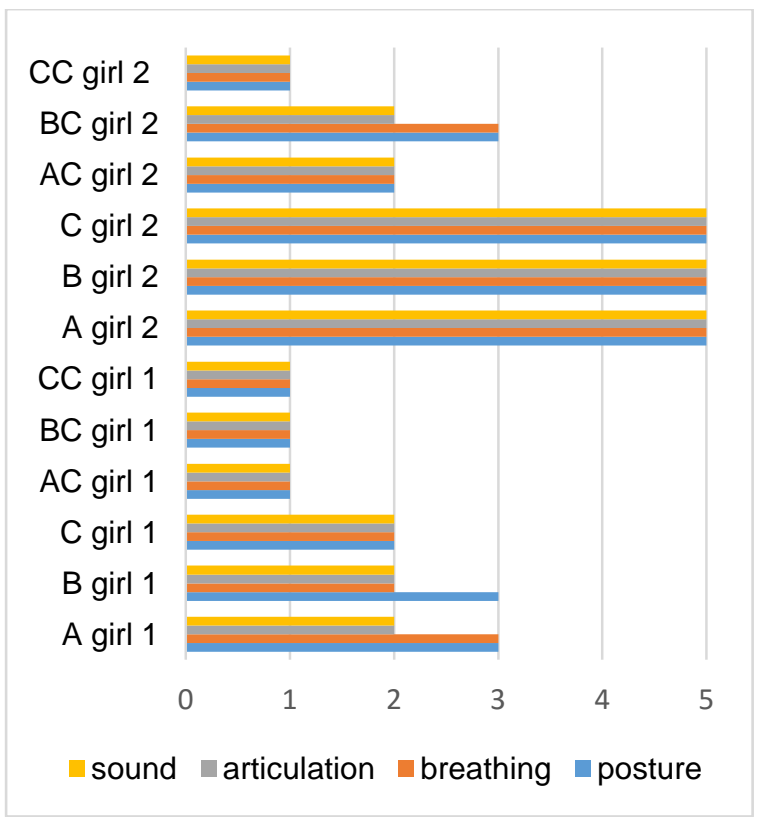

\section{Diagram 4. Correction of skinny singing voice}

1 = wrong, 2 = little better, 3 = medium, 4 = good $5=$ perfect

\section{Conclusions}

The results highlight considerable diversity in actual singing achievement in different tasks and different test contexts. In two years, all singing problems were breaked off. Healthy singing voice of children should be light, small, in the nature of headvoice, high-voice, shiny, sonorous, soaring, floaty, mobile, not veiled voice, not sophisticated, without pressing, not too loud, softly in low register.

Children's singing development is both varied and multifaceted, and this has considerable implications for teaching and assessing singing as well as other forms of music-making that depend on singing and singing quality in the years of school. A well-planned and efficiently executed exercises are essential for developing a good singing habit. Bescause the vocal cord is an extremely sensitive organ, it needs special care and trainig in order to have good voice production.

\section{References}

[1] Davidson, L. (1994)."Songsinging by young and old: a development approach to music", In: Aiello, R. (Ed.) Musical perceptions. Oxford University Press, New York, 99-130.

[2] Davies, A. D. M. \& Roberts, E. (1975). „The responsee of „monotones" to a programme of remedial training”. Journal of Research in Music Education, 23, 227-239.

[3] Dowling, W. J. (1999). „The development of music perception and cognition". In D. Deutsch (Ed), The psychology of music 2nd ed. San Diego, CA, Academic Press, 603-627.

[4] Flowers, P. J., \& Dunne-Sousa, D. (1990).’Pitchpattern accuracy, tonality, and vocal range in preschool children's singing". Journal of Research in Music Education, 38, 102-114.

[5] Fox, D. B (1990). „An analysis of the pitch characteristics of infant vocalizations". Psychomusicology, 9, 21-30.

[6] Gembris, H. (2006). „The development of musical abilities". In Colwell, R (Ed): MENC handbook of musical cognition, Oxford Universití Press, New York.

[7] Green, G. A. (1994). „Unison versus individual singing and elementary students' vocal pitch accuracy". Journal of Research in Music Education, 42, 105-114.

[8] Hargreaves, D. J. (1986). The developmental psychology of music. Cambridge University Press, Cambridge.

[9] Houlahan, M. and Ph. Tacka, (2008). Kodály Today - A Cognitive Approach to Elementary Music Education, Oxford University Press, New York.

[10] Levinowitz, L. M. (1989). „Measuring singing voice development in the elementary general music classroom". Journal of Research in Music Education, 46, 35-47.

[11] Metzler, F. (1962). „Strukturen kindlicher Melodik”. Psychologische Beiträge, 7, 218-284.

[12] Minkenberg, H. (1991). Das Musikerleben von Kindern im Alter von fünf bis zehn Jahren. Peter Lang, Frankfurt, Germany.

[13] Moog, H.(1976). The musical experience of the preschool child. Schott, London.

[14] Papousek, H. (1996). „Musicality in infancy research: Biological and cultural origins of early musicality". In I. Deliége \& J. A. Sloboda (Eds), Musical beginnings: Origins and development of musical competence. Oxford University Press, Oxford, 37-55. 
[15] Papousek, M. (1994). Vom ersten Schrei zum ersten Wort. Anfänge der Sprachentwicklung in der vorsprachlichen Kommunikation. Huber, Bern, Switzerland.

[16] Rutkowski, J. (1996). „The effectiveness of individual/small-group singing activities on kindergartners' use of singing voice and developmental music aptitude". Journal of Research in Music Education, 44, 353-368.

[17] Shuter-Dyson, R.,\& Gabriel, C. (1981). The psychology of musical ability. Methuen, London.

[18] Stadler Elmer, S. (2002). Kinder singen Lieder: Über den Prozess der Kultivierung des vokalen Ausdrucks. Waxmann, Münster

[19] Stadler, S (2000). Spiel und Nachahmung: Über die Entwicklung der elementaren musikalischen Aktivitäten. Nepomuk, Aaarau, Switzerland

[20] Welch, G. F. (1985). „A schema theory of how children learn to sing in tune". Psychology of music, 13, 318.

[21] Welch, G. F., \& White, P. (1994). „The developing voice Education and vocal efficiency - A physical perspective". Council for Research in Music Education, Bull.no. 119, 146-156.

[22] Welch, G. F. (2001). „The importance of singing”. Five to Seven. 1 (6), 35-37. 